\title{
Xanthobacter tagetidis sp. nov., an Organism Associated with Tagetes Species and Able To Grow on Substituted Thiophenes
}

\author{
A. NIKKI PADDEN,${ }^{1}$ FREDERICK A. RAINEY ${ }^{2} \dagger$ DONOVAN P. KELLY ${ }^{3}$ AND ANN P. WOOD ${ }^{1 *}$ \\ Division of Life Sciences, King's College London, London W8 $7 A H,{ }^{1}$ and Institute of Education, \\ University of Warwick, Coventry CV4 $7 A L,{ }^{3}$ England, and Deutsche Sammlung von \\ Mikroorganismen und Zellkulturen GmbH, D-38124 Braunschweig, Germany ${ }^{2}$
}

\begin{abstract}
Members of the marigold genus of flowering plants (the genus Tagetes), which synthesize and accumulate thiophene compounds in their roots, were investigated as potential sources of bacteria able to degrade substituted thiophenes. Batch and continuous enrichment cultures inoculated with compost from root balls of Tagetes patula and Tagetes erecta reproducibly produced the same predominant type of bacterium when they were supplied with thiophene-2-carboxylate (T2C) or thiophene-2-acetate (T2A) as a carbon and energy substrate. This organism was a yellow-pigmented, neutrophilic, mesophilic, gram-negative, pleomorphic, rodshaped bacterium, which we classify as a new species of the genus Xanthobacter, Xanthobacter tagetidis; strain TagT2C (= DSM 11105) is the type strain. Strain TagT2C ${ }^{\mathrm{T}}$ ( $\mathrm{T}=$ type strain) grew on simple thiophenes, such as $\mathrm{T} 2 \mathrm{C}$, thiophene-3-carboxylate, and $\mathrm{T} 2 \mathrm{~A}$, on analogs of these compounds (pyrrole-2-carboxylate and furan2-carboxylate), and on the condensed thiophene dibenzothiophene. $X$. tagetidis was facultatively autotrophic, fixing carbon dioxide by means of ribulose bisphosphate carboxylase, and was able to grow on hydrogen, thiosulfate, or sulfide as an energy substrate. It also grew on a wide range of other heterotrophic, chemolithotrophic, and methylotrophic substrates. Its growth on $\mathrm{T} 2 \mathrm{C}$ was optimal at 28 to $31^{\circ} \mathrm{C}$ and $\mathrm{pH} 7.6$ to 7.8 , and the maximum growth rate in batch culture was $0.22 \mathrm{~h}^{-1}$. The DNA base composition of $X$. tagetidis is $68 \mathrm{~mol} \%$ G+C. A $16 S$ ribosomal DNA sequence analysis of strain TagT2 $C^{\mathrm{T}}$ showed that this organism represents a distinct lineage within the Aquabacter-Azorhizobium-Xanthobacter cluster of the alpha-2 subclass of the Proteobacteria. Discrimination of $X$. tagetidis from the other genera in this group and from other Xanthobacter species is discussed.
\end{abstract}

In contrast to the extensive studies of bacteria that effect inorganic sulfur turnover in natural environments, soil microorganisms involved in the degradation of organic sulfur compounds other than sulfur amino acids have been almost completely neglected. Plants effect the turnover of enormous amounts of sulfur (up to $10 \mathrm{Gt}$ of $\mathrm{S}$ per year), but the microbiological processes associated with this, which involve living plants and decay of plants, have not been comprehensively studied and described.

Tagetes plants are well-documented producers of thiophene compounds (bi- and terthienyls), which can constitute almost $1 \%$ of the normal root mass $(4,16,29,39)$. These compounds are variably excreted by the plant cells, in response to altering environmental conditions, and have been shown to have significant fungicidal, insecticidal, and allergenic activities $(14,31$, $35,36)$. The root balls of growing Tagetes patula and Tagetes erecta plants have been used to enrich for novel thiophenedegrading microorganisms. In previous studies on the biological degradation of thiophene, workers have used anthropogenically contaminated soil or water as enrichment samples, and many workers have concentrated on dibenzothiophene as a model substrate, particularly for the potential desulfurization of fossil fuels $(24,30,42)$. There have been far fewer studies on the microbial breakdown of the simpler substituted thiophenes $(1,2,6,7)$.

In this study we used the simple thiophene derivatives thio-

* Corresponding author. Mailing address: Division of Life Sciences, King's College London, Campden Hill Road, London W8 7AH, England. Phone: 44171333 4344. Fax: 44171333 4500. E-mail: ann .p.wood@kcl.ac.uk.

$\dagger$ Present address: Department of Microbiology, Louisiana State University, Baton Rouge, LA 70803. phene-2-carboxylate (T2C) and thiophene-2-acetate (T2A) as enrichment substrates. Batch and continuous chemostat enrichment cultures were used to isolate pure cultures or consortia capable of T2C or T2A degradation. This work resulted in the isolation of a novel Xanthobacter species.

\section{MATERIALS AND METHODS}

Growth of $T$. patula and $T$. erecta. T. patula (French marigold) and T. erecto (African marigold) plants were grown in a commercially available material called Vitax Q4 multipurpose compost (Vitax Home and Garden Products, Leicester, United Kingdom) in plastic plant pots (diameter, 9 or $13 \mathrm{~cm}$ ) in the open air. All references to compost below are references to this support material. Compost samples were obtained from around the roots of plants of each of the species, including both yellow- and orange-flowered varieties of $T$. erecta, by using plants of different ages, and these samples were used as inocula for batch and chemostat enrichment cultures. For batch enrichment cultures we used compost samples from seedlings (height, 4 to $5 \mathrm{~cm}$ ) and from plants grown to maturity (and flower production). For chemostat enrichment cultures we used compost from mature plants of T. patula.

Growth media, methods used for batch culture and continuous culture, and analytical procedures. The medium used for isolation and pure-culture growth and maintenance contained (per liter of distilled water) $7.9 \mathrm{~g}$ of $\mathrm{Na}_{2} \mathrm{HPO}_{4}$. $2 \mathrm{H}_{2} \mathrm{O}, 1.5 \mathrm{~g}$ of $\mathrm{KH}_{2} \mathrm{PO}_{4}, 0.4 \mathrm{~g}$ of $\mathrm{NH}_{4} \mathrm{Cl}, 0.1 \mathrm{~g}$ of $\mathrm{MgSO}_{4} \cdot 7 \mathrm{H}_{2} \mathrm{O}$, and $10 \mathrm{ml}$ of a trace metal solution (40); the initial pH of this medium was 7.3. Substrates and phosphates were separately sterilized and mixed with the other components when they were cool. To produce media having different $\mathrm{pH}$ values, $1 \mathrm{M} \mathrm{NaOH}$ was added as necessary. For solid media, Oxoid bacteriological agar ( $15 \mathrm{~g} /$ liter $)$ was added, and to show $\mathrm{pH}$ changes, a saturated phenol red solution $(1 \%$, $\mathrm{vol} / \mathrm{vol}$ ) was added. Stock cultures were maintained on agar slants of the basic mineral medium supplemented with T2C $(2.5 \mathrm{mM})$ or sodium acetate $(5 \mathrm{mM})$. For autotrophic growth on hydrogen, the basal medium was supplemented with $\mathrm{NiSO}_{4}(0.1 \mu \mathrm{M})$. Erlenmeyer flasks (headspace volume, $300 \mathrm{ml}$ ) sealed with Subaseal vaccine stoppers were flushed with $\mathrm{H}_{2}$ before a bacterial culture ( 25 $\mathrm{ml}), \mathrm{NaHCO}_{3}(10 \mathrm{mM})$, and $\mathrm{O}_{2}(30 \mathrm{ml})$ were added. Fixation of dinitrogen was tested by using heterotrophic cultures growing on $\mathrm{T} 2 \mathrm{C}(2.5 \mathrm{mM})$ in sealed flasks that either contained normal air or were flushed with a nitrogen-air mixture (95:5, $\mathrm{vol} / \mathrm{vol})$ before the flasks were sealed to provide oxygen at a concentration of $1 \%(\mathrm{vol} / \mathrm{vol})$. To avoid transfer of fixed nitrogen into the nitrogen-free medium, the flasks were inoculated with colonies from agar plates. Growth (with denitrification) on $\mathrm{T} 2 \mathrm{C}(2.5 \mathrm{mM})$ or acetate $(10 \mathrm{mM})$ was tested in liquid 
medium (44) supplemented with $\mathrm{KNO}_{3}(25 \mathrm{mM})$ and $\mathrm{NaHCO}_{3}(24 \mathrm{mM})$ in argon-flushed flasks or in completely filled bottles (volume, 25 to $100 \mathrm{ml}$ ). Aerobic cultures ( 25 to $100 \mathrm{ml}$ ) in 250 -ml conical flasks were either shaken in an orbital incubator (New Brunswick Scientific, Hatfield, United Kingdom) at 200 $\mathrm{rpm}$ or incubated statically. The routine growth temperature was $30^{\circ} \mathrm{C}$. The effects of different temperatures $\left(4\right.$ to $\left.69^{\circ} \mathrm{C}\right)$ and different $\mathrm{pH}$ values $(7.3$ to 8.7$)$ on growth were tested by using T2C-grown batch cultures (in liquid media or on agar media) and chemostat batch cultures (1.75 liters) growing on thiosulfate (10 $\mathrm{mM})$ that were aerated $\left(100 \mathrm{ml} \mathrm{min}^{-1}\right)$ but otherwise were as described previously (18). Chemostat cultures (1.75 liters) were maintained at $30 \pm 2^{\circ} \mathrm{C}$ and $\mathrm{pH}$ $7.3 \pm 0.2$ (by automatic titration with $2 \mathrm{M} \mathrm{Na}_{2} \mathrm{CO}_{3}$ ) with air flow at a rate of 200 $\mathrm{ml} / \mathrm{min}$ and were stirred at $200 \mathrm{rpm}$. The chemostat equipment was supplied by LH Fermentation, Ltd., Reading, United Kingdom, and New Brunswick Scientific, Hatfield, United Kingdom. Growth was monitored by visually observing turbidity, by measuring optical density at $440 \mathrm{~nm}$, and by measuring the disappearance of substrate. Organism dry weights and protein contents were determined as described previously (46). Thiosulfate and tetrathionate were assayed by the cyanolysis method $(22,23)$, nitrate was assayed by the method of Cawse (5), and nitrite was assayed by using commercial Griess-Ilosvay reagents (Merck Poole, United Kingdom) and measuring $A_{525}$. T2C was assayed by monitoring $A_{245}$ (molar extinction coefficient, $8.6 \times 10^{3}$ liter $/ \mathrm{mol} / \mathrm{cm} \mathrm{[7])}$

A wide range of growth substrates were tested at the concentrations given below. Substituted thiophenes and other toxic, volatile, or unstable substrates were generally sterilized by filtration, but some compounds (including carbon disulfide, carbonyl sulfide, dimethyl sulfide, methanethiol, thiophene, 3-methylthiophene, and $\alpha$-terthiophene) were used without prior sterilization. Incubations with volatile substrates were carried out in Ouickfit flasks with Subaseal stoppers, into which substrates were injected.

To test $\mathrm{T} 2 \mathrm{C}$ as a sulfur, carbon, and energy substrate, the sulfates in the original medium were replaced by chlorides or nitrates, and the initial inoculum was subcultured five times in sulfate-free medium to obtain sulfate-free growth To test alternative nitrogen sources, $\mathrm{NH}_{4} \mathrm{Cl}$ and the trace metal solution were omitted from the medium. An API 20E multitest system (bioMerieux, Marcy l'Etoile, France) was used to determine the physiological characteristics of some isolates.

Antibiotic sensitivity was tested by using Difco Dispence-O-Disc minifilters on agar plates containing $\mathrm{T} 2 \mathrm{C}$ and nutrient broth.

Ribulose bisphosphate carboxylase was assayed in cell extracts obtained from thiosulfate-grown organisms, as described by Jordan et al. (18).

Enrichment cultures and isolation of organisms. (i) Batch enrichment cultures. Samples $(10 \mathrm{~g})$ of compost removed from $T$. patula root balls were added to $100-\mathrm{ml}$ portions of liquid medium ( $\mathrm{pH} 7.3)$ containing T2C or T2A $(2.5 \mathrm{mM})$ as an enrichment substrate and were incubated in 250-ml flasks shaken in air at $30^{\circ} \mathrm{C}$. For enrichment cultures for denitrifying organisms we used 2.5 -g portions of compost samples in $25-\mathrm{ml}$ bottles completely filled with medium supplemented with $\mathrm{T} 2 \mathrm{C}$ and $\mathrm{KNO}_{3}(25 \mathrm{mM})$. Cultures in which growth occurred were subcultured three times into fresh medium before they were streaked onto agar plates for single-colony isolation. For subsequent enrichment cultures we used standard T2C batch culture conditions and compost samples from root balls of two types (yellow and orange) of $T$. erecta and from root balls of $T$. patula. Samples of unused compost were incubated in medium containing $\mathrm{T} 2 \mathrm{C}$ as controls. After incubation, dilution plates of each culture were prepared to check the relative abundance of isolates.

(ii) Low-dilution-rate continuous enrichment cultures. Compost samples from T. patula root balls were inoculated into three separate chemostats, and a period of initial batch growth was followed by the following conditions: in chemostat $i$ $2.5 \mathrm{mM} \mathrm{T} 2 \mathrm{~A}$ and a dilution rate of $0.065 \mathrm{~h}^{-1}$; in chemostat ii, $2.5 \mathrm{mM} \mathrm{T2C}$ and a dilution rate of $0.05 \mathrm{~h}^{-1}$; and in chemostat iii, $2.5 \mathrm{mM} \mathrm{T2C}$ and a dilution rate which increased from 0.013 to $0.039 \mathrm{~h}^{-1}$. Each chemostat culture was grown for 5 to 7 weeks. Dilution plates were prepared during growth in batch culture as the amount of substrate decreased, immediately before substrate pumps were started, at subsequent intervals corresponding to every three culture volume changes, and at the conclusion of the experiment. The substrate used in the agar plates was either acetate $(5 \mathrm{mM})$, nutrient broth $(0.1 \%)$, thiosulfate $(20 \mathrm{mM})$, T2A $(2.5 \mathrm{mM})$, or T2C $(2.5 \mathrm{mM})$ or there was no substrate, which allowed us to assess the total numbers of heterotrophs, chemolithoautotrophs, primary thiophene users, and oligotrophic opportunists.

Microscopy. Standard light microscopy techniques were used together with scanning (Philips model 501 SEM) and transmission (JEOL model JEM-100 CXII and Philips model 501G) electron microscopes.

Substrate oxidation kinetics. Organisms grown on T2C $(2.5 \mathrm{mM})$ in a chemostat culture (dilution rate, $0.034 \mathrm{~h}^{-1}$ ) at $\mathrm{pH} 7.3$ and $30^{\circ} \mathrm{C}$ were used in an oxygen electrode assembly (18) to determine the range of substrates oxidized and the kinetics of substrate oxidation.

DNA $\mathbf{G}+\mathbf{C}$ ratios. DNA was isolated from cells grown on $\mathrm{T} 2 \mathrm{C}(2.5 \mathrm{mM})$ by using a modification of the procedure of Marmur (27), and the $\mathrm{G}+\mathrm{C}$ content was determined by the spectrophotometric method of Fredericq et al. (13) with a Hewlett-Packard model 8452A diode array spectrophotometer (Anachem, Luton, United Kingdom) or a model CE272 UV spectrophotometer (Cecil Instruments, Cambridge, United Kingdom) and by the melting point method (26) by using 1 or $2^{\circ} \mathrm{C}$ temperature increments between 75 and $91^{\circ} \mathrm{C}$. DNA from Esch. erichia coli B (= ATCC 11303) was used as the standard.
$16 S$ rDNA sequence determination and analysis. Genomic DNAs were extracted from strains TagT $2 C^{\mathrm{T}}$ ( $\mathrm{T}=$ type strain) and A2 for PCR-mediated amplification of the $16 \mathrm{~S}$ ribosomal DNA (rDNA) as described by Rainey et al. (33). The purified PCR products were directly sequenced by using previously described protocols (33), and the sequence reaction mixtures were electrophoresed by using a model 373A automatic DNA sequencer (Applied Biosystems, Foster City, Calif.). The $16 \mathrm{~S}$ rDNA sequence was manually aligned with the $16 \mathrm{~S}$ rDNA sequences of members of the alpha-2 subclass of the Proteobacteria by using the ae 2 editor (25). Evolutionary distances were calculated by the method of Jukes and Cantor (20). Phylogenetic dendrograms were constructed by using tree algorithms contained in the PHYLIP package (12). Tree topologies were evaluated by performing bootstrap analyses (11) of the neighbor-joining data with 1,000 resamplings.

Ubiquinone extraction. The ubiquinone fraction was isolated, purified, and identified by the method described for Thiobacillus tepidarius (45) and modified by Jordan et al. (18) by using cells grown in a chemostat on T2C $(2.5 \mathrm{mM})$ at $\mathrm{pH}$ 7.3 and a dilution rate of $0.094 \mathrm{~h}^{-1}$. The standards used for ubiquinone chromatography were commercial coenzyme Q10 and coenzyme Q8 prepared from Thiobacillus ferrooxidans.

Chemicals. All chemicals were analytical grade unless indicated otherwise. Methanethiol, proteinase $\mathrm{K}$, ubiquinone 30 (coenzyme Q10), RNase, and E. coli DNA were obtained from Sigma, Poole, United Kingdom. Methylamines, thiophene compounds, dimethyl sulfide, carbonyl sulfide, and carbon disulfide were obtained from Aldrich Chemical Co., Gillingham, United Kingdom.

Nucleotide sequence accession number. The 16S rDNA sequence determined for strain TagT2 $\mathrm{C}^{\mathrm{T}}$ has been deposited in the EMBL database under accession number X99469.

\section{RESULTS}

Enrichment in batch culture from compost supporting $T$. patula or T. erecta. Aerobic enrichment cultures obtained from the root balls of $T$. patula produced yellow colonies on medium containing T2C; similar colonies also grew on thiosulfate and T2A. A pure culture obtained from the enrichment cultures was designated strain TagT2 $\mathrm{C}^{\mathrm{T}}$ prior to further characterization. A second series of aerobic enrichment cultures inoculated with compost in which $T$. erecta and $T$. patula had been grown yielded similar yellow isolates in all cases. Recently, an apparently identical organism was isolated from a T2C-containing enrichment culture obtained from the root ball of another species, Tagetes minuta (30a). Enrichments cultures prepared with fresh, unsterilized compost in which no Tagetes plants had been grown yielded no organisms capable of growth on T2C No growth on T2C was observed in enrichment cultures under denitrifying conditions.

Enrichment from $T$. patula compost by using continuous culture. Up to 13 colony types were seen in the initial samples from the chemostats. Most of these colony types accounted for $<1 \%$ of the total population recovered on agar media containing acetate or nutrient broth or thiosulfate or T2A or T2C as the substrate. In all cases the predominant organisms produced yellow colonies (as did strain TagT2C $\mathrm{C}^{\mathrm{T}}$ ), and this dominance was observed early in the chemostat enrichment cultures, even at the lowest dilution rates. In all three chemostat procedures, the cultures were dominated ( 92 to $100 \%$ of all of the organisms) by strains that produced yellow colonies (TagT2 $\mathrm{C}^{\mathrm{T}}$ type) on $\mathrm{T} 2 \mathrm{C}$ or $\mathrm{T} 2 \mathrm{~A}$. One representative isolate, designated strain A2, which was derived from chemostat ii, was used for comparison with strain TagT $2 C^{\mathrm{T}}$ from the batch enrichment cultures.

Selection of a pure culture for further study. Strains TagT $2 \mathrm{C}^{\mathrm{T}}$ and $\mathrm{A} 2$ were found to be indistinguishable from each other on the basis of colony morphology, cell morphology, and growth on T2C. Strain TagT $2 C^{\mathrm{T}}$ was studied in detail to determine its characteristics, and a detailed comparison with strain A2 was performed. The results (see below) indicated that these strains were physiologically and biochemically identical, leading to the conclusion that the same type of organism predominated regardless of the conditions employed for enrichment culture. 


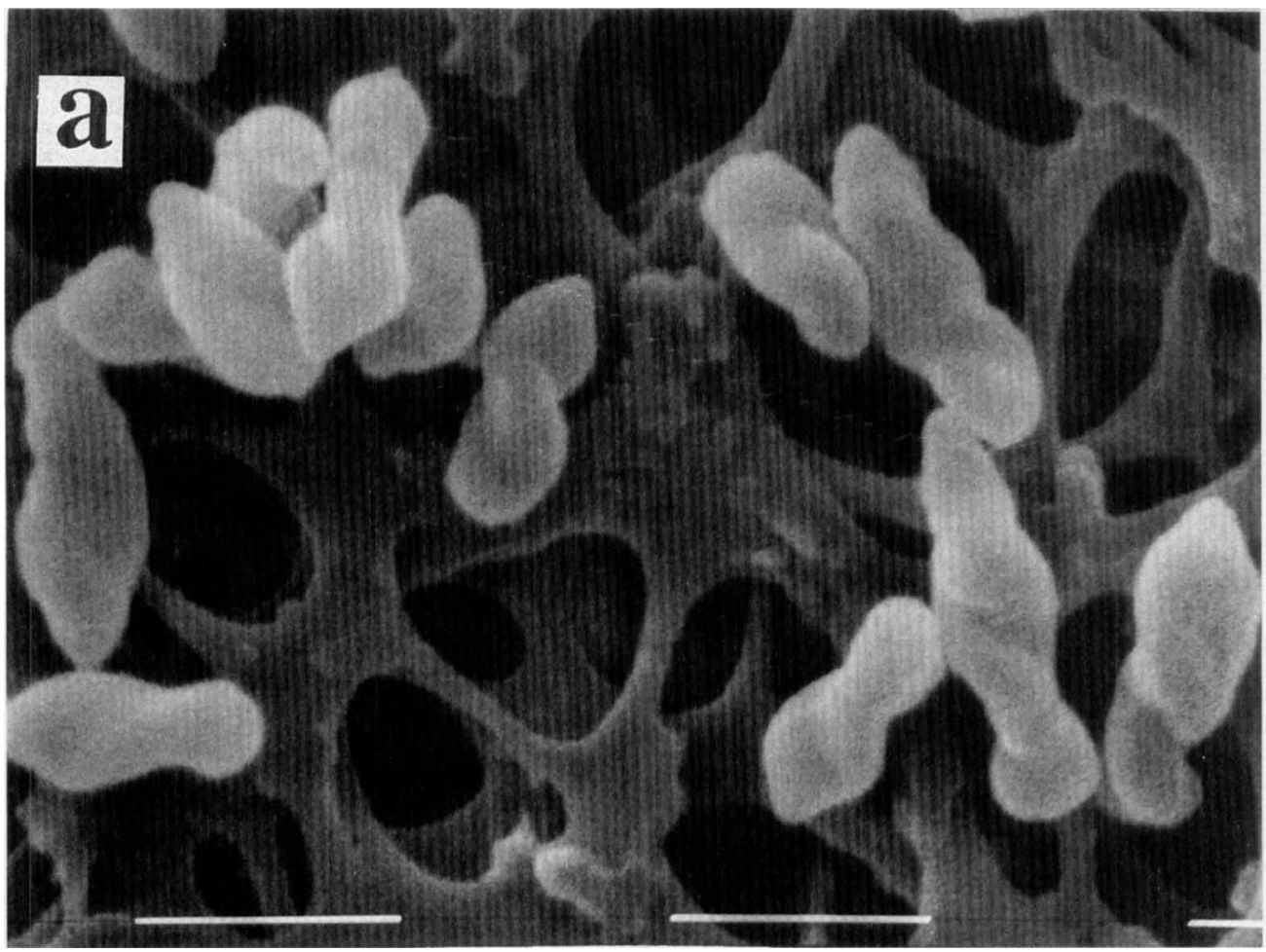

FIG. 1. Electron micrographs of $X$. tagetidis TagT2C $C^{\mathrm{T}}$. (a) Scanning electron microscope image, showing the irregular shape and twisting morphology of the cells. Bar $=1 \mu \mathrm{m}$. (b and c) Transmission electron microscope images of thin sections, showing the irregular cell shape and basal sections of peritrichous flagella. Bars = $0.1 \mu \mathrm{m}$.

Morphology. Colonies of strains TagT2 $\mathrm{C}^{\mathrm{T}}$ and A2 were egg yolk yellow, low convex, regular, smooth, and mucoid and became slightly raised and irregular in shape with age. As determined by light microscopy, the cells of both strains were short, fat, motile, gram-negative rods $(0.5$ by $1.0 \mu \mathrm{m})$ with capsules and large, dark inclusion bodies which occurred at one or both ends of the cells, but no endospores were formed. Cells of strain TagT $2 \mathrm{C}^{\mathrm{T}}$ grown on succinate-containing medium and observed by light microscopy exhibited pleomorphism, including bent cells, as described for the type species of the genus Xanthobacter, Xanthobacter autotrophicus (43). Scanning electron microscopy images showed that strain TagT2C ${ }^{\mathrm{T}}$ cells were irregular and resembled fusilliform spirals (Fig. 1), while transmission electron microscopy revealed irregular, pleomorphic cells with peritrichous flagella (Fig. 1).

Physiological characteristics. Strains TagT $2 \mathrm{C}^{\mathrm{T}}$ and $\mathrm{A} 2$ were oxidase positive, but were negative for phosphatase activity, indole production, the methyl red test, the Voges-Proskauer test, and glucose fermentation. Strain TagT2C ${ }^{\mathrm{T}}$ was catalase positive (strain A2 was not tested). Strain TagT $2 C^{\mathrm{T}}$ grew at temperatures from 4 to $43^{\circ} \mathrm{C}$, and the optimum temperature was 28 to $31^{\circ} \mathrm{C}$. The $\mathrm{pH}$ range for strain $\mathrm{TagT} 2 \mathrm{C}^{\mathrm{T}}$ was 6.8 to 8.7 , and the optimum $\mathrm{pH}$ was 7.6 to 7.8. Growth was not microaerophilic, but under static conditions the batch culture growth rate on $\mathrm{T} 2 \mathrm{C}$ was initially as high as the growth rate in a shaken culture $\left(0.13 \mathrm{~h}^{-1}\right.$ at an initial $\mathrm{pH}$ of 7.3$)$ and growth was accompanied by less slime formation.

The distinctive yellow pigment was formed during both heterotrophic growth and autotrophic growth. It was not water soluble in exponentially growing cells, but in dying, lysing, or stressed cells some of the pigment diffused into the medium. The identity of the pigment was not investigated further.

As determined with the API $20 \mathrm{E}$ test system, strains TagT2C ${ }^{\mathrm{T}}$ and $A 2$ were identical with respect to the presence of $\beta$-galactosidase (weak), arginine dihydrolase, lysine decarboxylase, ornithine decarboxylase, urease, tryptophan deaminase (weak), gelatinase, and cytochrome oxidase activities; production of acetoin (during fermentation of glucose, glycerol, or pyruvate); use of citrate, mannitol, inositol, sorbitol, rhamnose, sucrose, melibiose, amygdalin, and arabinose; production of indole (negative); production of hydrogen sulfide from thiosulfate (negative); and production of nitrite from nitrate (negative). These tests showed that the two strains are very similar, and while they did not allow us to determine the genus to which the strains belong, they did eliminate the possibility that the strains are members of a large number of genera, including the genera Achromobacter, Acinetobacter, Aeromonas, Alcaligenes, Citrobacter, Erwinia, Escherichia, Flavobacterium, Kluyvera, Moraxella, and Pseudomonas.

The substrates that supported growth of strain TagT2C $\mathrm{C}^{\mathrm{T}}$ (as sole sources of energy and carbon), sometimes after lag periods of up to 7 days, were T2C $(2.5 \mathrm{mM})$, T2A ( $2.5 \mathrm{mM})$, thiophene-3-carboxylate $(2.5 \mathrm{mM})$, pyrrole-2-carboxylate $(10 \mathrm{mM})$, furan-2-carboxylate $(10 \mathrm{mM})$, dibenzothiophene $(2.5 \mathrm{mM})$, methylamine $\left(20 \mathrm{mM}\right.$, with $\left.\mathrm{NaHCO}_{3}\right)$, methanol $(20 \mathrm{mM})$ (weak growth), dimethyl sulfide $(2.5 \mathrm{mM})$, methanethiol $(2.5$ $\mathrm{mM})$, formate $(25 \mathrm{mM})$, acetate $(10 \mathrm{mM})$, ethanol $(20 \mathrm{mM})$, succinate $(10 \mathrm{mM})$, pyruvate $(5 \mathrm{mM})$, citrate $(5 \mathrm{mM})$, yeast extract $(0.01 \%)$, nutrient broth $(0.1 \%)$, galactose $(20 \mathrm{mM})$ (good growth), sucrose $(20 \mathrm{mM})$, fructose $(20 \mathrm{mM})$, and glucose $(20 \mathrm{mM})$ (poor growth). In addition, the following compounds supported growth as energy substrates (with autotrophic fixation of carbon dioxide): thiosulfate $(20 \mathrm{mM})$, tetrathionate $(5 \mathrm{mM}$, with $10 \mathrm{mM} \mathrm{NaHCO}$ ), sulfide $(2.5 \mathrm{mM})$ hydrogen (see Materials and Methods), carbonyl sulfide (4.0 $\mathrm{mM})$, and carbon disulfide $(2.5 \mathrm{mM})$ (best when provided with 


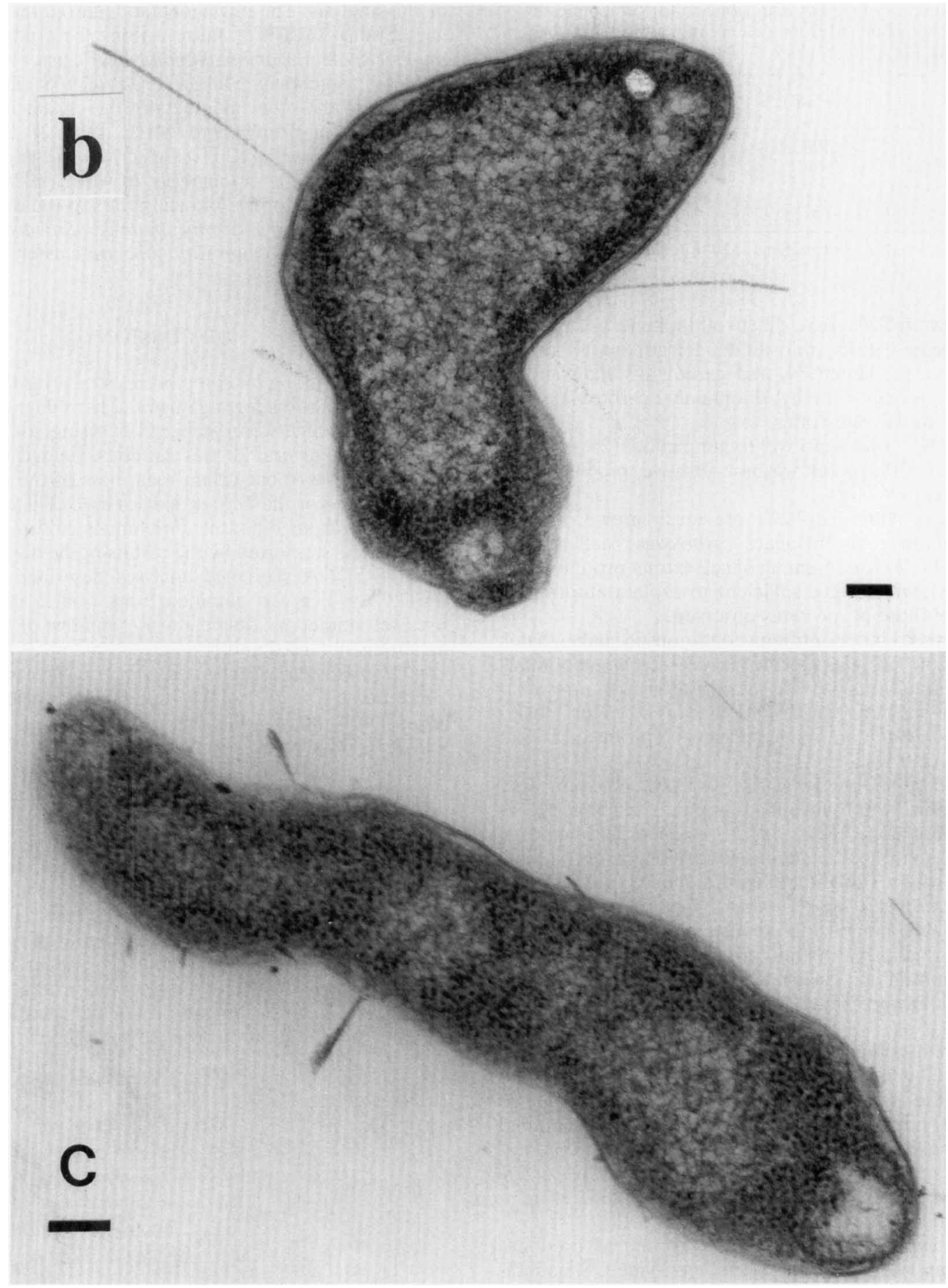

FIG. 1-Continued.

$0.01 \%$ [wt/vol] yeast extract). In sulfate-free medium, T2C supported growth of strain TagT2 $\mathrm{C}^{\mathrm{T}}$ as a carbon, energy, and sulfur source. Substrates that did not support growth (at a concentration of $2.5 \mathrm{mM}$ ) were thiophene, 3-methyl-thiophene, 5-methyl-thiophene-2-carboxylate, 3-methyl-thiophene-2-carboxylate, $\alpha$-terthiophene, and thiophene-3-acetate. KSCN did not act as a growth substrate or nitrogen source. Molecular dinitrogen served as a sole source of nitrogen for growth on $\mathrm{T} 2 \mathrm{C}$; growth was sustained through three subcultures on me- dium lacking $\mathrm{NH}_{4} \mathrm{Cl}$ and was comparable in flasks with a normal air atmosphere and in sealed flasks containing only $1 \%$ (vol/vol) oxygen. The growth yield with dinitrogen as the only source of nitrogen was $50 \pm 10 \mathrm{~g}$ (dry weight) $/ \mathrm{mol}$ of T2C (eight determinations), compared with yields of $74 \pm 5 \mathrm{~g} / \mathrm{mol}$ of $\mathrm{T} 2 \mathrm{C}$ with $\mathrm{NH}_{4} \mathrm{Cl}$ as the nitrogen source. Growth with denitrification did not occur on $\mathrm{T} 2 \mathrm{C}$ or acetate, although partial denitrification to nitrite did occur with acetate.

Strains TagT2C $\mathrm{C}^{\mathbf{T}}$ and $\mathrm{A} 2$ appeared to be identical in their 
TABLE 1. Kinetics of oxidation of some sulfur compounds by strain TagT $2 \mathrm{C}^{\mathrm{T}}$ obtained from a chemostat culture growing

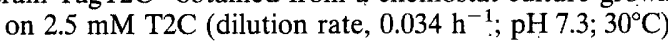

\begin{tabular}{|c|c|c|}
\hline Substrate $^{a}$ & $K_{m}(\mu \mathrm{M})$ & $\begin{array}{c}V_{\max }\left(\mathrm{nmol} \mathrm{O}_{2} / \mathrm{min} / \mathrm{mg}\right. \\
{[\text { dry wt] })}\end{array}$ \\
\hline $\mathrm{T} 2 \mathrm{C}$ & 198 & 304 \\
\hline Thiosulfate & 14 & 81 \\
\hline Tetrathionate & 7 & 75 \\
\hline Sulfide & 67 & 135 \\
\hline
\end{tabular}

${ }^{a}$ Substrates were tested at concentrations of 10 to $100 \mu \mathrm{M}$.

abilities to grow on T2C, T2A, dibenzothiophene, acetate, nutrient broth, yeast extract, thiosulfate, tetrathionate, sulfide, dimethyl sulfide, methanethiol, and carbon disulfide and in their inabilities to use 5-methyl-thiophene-2-carboxylate and thiocyanate as growth substrates.

Strain TagT2 $\mathrm{C}^{\mathrm{T}}$ was sensitive to ampicillin $(25 \mu \mathrm{g})$ and chloramphenicol $(30 \mu \mathrm{g})$, but was not sensitive to penicillin (1 $\mathrm{U})$ and tetracycline $(5 \mu \mathrm{g})$.

Cell extracts of strain TagT $2 C^{\mathrm{T}}$ previously grown on thiosulfate had ribulose bisphosphate carboxylase activities of $108 \pm 6 \mathrm{nmol}$ of $\mathrm{CO}_{2}$ fixed $/ \mathrm{min} / \mathrm{mg}$ of cell extract protein (eight determinations), which were sufficient to explain autotrophic growth on thiosulfate at the rates observed.

Growth kinetics. Under optimum conditions in shaken batch cultures grown on $\mathrm{T} 2 \mathrm{C}$, the specific growth rate was about 0.22 $\mathrm{h}^{-1}$. Chemostat cultures were not grown at growth rates near this maximum specific growth rate because the organisms leaked a yellow pigment into the medium and produced $\mathrm{H}_{2} \mathrm{~S}$ at a dilution rate of $0.13 \mathrm{~h}^{-1}$.

Substrate oxidation kinetics. Strain TagT2 $\mathrm{C}^{\mathrm{T}}$ grown on T2C was able to oxidize the following compounds (each at a concentration of $100 \mu \mathrm{M}$ ): T2C, T2A, thiophene-3-carboxylate, acetate, formate, citrate, thiosulfate, tetrathionate, and sulfide. Organisms grown on T2C did not oxidize glucose $(100 \mu \mathrm{M})$ or thiophene-3-acetate $(10$ or $100 \mu \mathrm{M})$. Kinetic constants were determined (Table 1), and these constants showed that T2Cgrown bacteria had a high affinity for inorganic sulfur species (which may be potentially toxic intermediates in thiophene ring degradation) but a surprisingly low affinity for the growth substrate, $\mathrm{T} 2 \mathrm{C}$.

DNA base composition. The $\mathrm{G}+\mathrm{C}$ content of strain TagT2C $\mathrm{C}^{\mathrm{T}}$ was determined by using two separate DNA preparations and two methods, the $A_{260} / A_{280}$ ratio method of Fredericq et al. and the melting point method. The $\mathrm{G}+\mathrm{C}$ contents determined were $67 \pm 1$ mol\% (method of Fredericq et al.; nine determinations) and $71 \pm 3 \mathrm{~mol} \%$ (melting point method; five determinations). The mean \pm standard deviation for all determinations was $68 \pm 2 \mathrm{~mol} \% \mathrm{G}+\mathrm{C}$.

Ubiquinone content. Strain TagT $2 \mathrm{C}^{\mathrm{T}}$ contained predominantly coenzyme Q10, as well as some coenzyme Q8, as indicated by a compound that had the same $R_{f}$ as standard coenzyme Q8 and an absorbance peak at $280 \mathrm{~nm}$.

16S rDNA sequence analysis. An almost complete $16 \mathrm{~S}$ rDNA sequence comprising 1,417 nucleotides $(>95 \%$ of the $E$. coli sequence [3]) was determined for strain TagT $2 C^{T}$. A comparative sequence analysis performed with $16 \mathrm{~S}$ rDNAs from two other putatively identical strains, including strain $\mathrm{A} 2$, showed that all three organisms exhibited $100 \%$ homology with each other.

The phylogenetic dendrogram shown in Fig. 2 was constructed from evolutionary distances by the neighbor-joining method (37). A total of 1,371 nucleotides present in all strains between positions 35 and 1488 (E. coli positions [3]) were used for this analysis. The phylogenetic dendrogram (Fig. 2) shows that strain TagT2C $\mathrm{C}^{\mathrm{T}}$ falls within the radiation of the Aquabacter-Azorhizobium-Xanthobacter cluster. It represents a distinct lineage that exhibits levels of $16 \mathrm{~S}$ rDNA sequence similarity to the other members of the cluster included in the analysis ranging from 96.9 to $98.1 \%$ (Table 2). The equidistant position of strain TagT2 $\mathrm{C}^{\mathrm{T}}$ (Fig. 2) was not supported by the results of the bootstrap analysis, in which values of less than $54 \%$ were found for the branch points of the distinct lineages within the Aquabacter-Azorhizobium-Xanthobacter cluster. The Aquabacter-Azorhizobium-Xanthobacter cluster was recovered in all analyses $(100 \%)$.

\section{DISCUSSION}

The most striking outcome of this study was the finding that enrichment cultures for organisms able to degrade substituted thiophenes, which were prepared by using compost removed from roots of several Tagetes varieties, yielded the same morphological type of bacterium regardless of the method of enrichment used or the Tagetes species used. The conclusion that the isolates from different enrichment cultures were indeed identical was supported by the results of the physiological tests and $16 \mathrm{~S}$ rDNA sequence analyses described above. Strain TagT2 $C^{\mathrm{T}}$, which was obtained from a batch enrichment culture, was studied as a typical representative of the T2C-utilizing strains obtained and is described below as a member of a novel Xanthobacter species, Xanthobacter tagetidis.

Strain TagT2C ${ }^{\mathrm{T}}$ is distinct from the few previously described T2C-using bacteria, which were isolated from sewage or oilpolluted soil and water; these bacteria included Flavobacterium $(1,2)$, Vibrio $(10)$, and Rhodococcus $(21)$ strains, E. coli mutants (19), and an unclassified heterotrophic rod-shaped organism $(6,7)$. Strain TagT2 $C^{\mathrm{T}}$ is striking because of its metabolic versatility; it is able to grow heterotrophically on a wide range of organic nutrients, including substituted thiophenes, chemolithoautotrophically, and methylotrophically. Its ability to grow under static growth conditions may reflect its habitat, root-associated soil particles where aeration may be low. Its production of extracellular slime material is also consistent with its association with root surfaces, where its attachment and survival in the substrate-producing environment may be helped by its slime production. It would be very interesting to

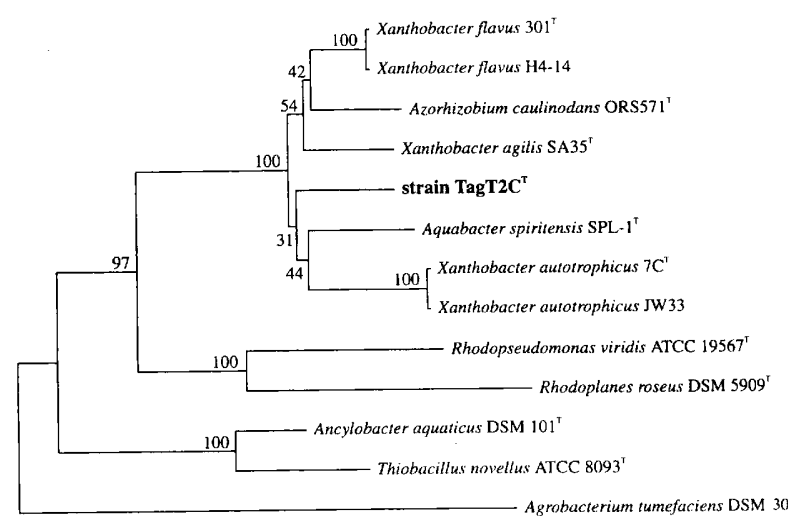

FIG. 2. 16S rDNA sequence-based phylogenetic dendrogram constructed from evolutionary distances by using the neighbor-joining method (37). Scale bar $=2.5$ inferred nucleotide substitutions per 100 nucleotides. The numbers a the branch points are bootstrap values. 
TABLE 2. Levels of $16 \mathrm{~S}$ rDNA sequence similarity between strain $\operatorname{TagT}^{\mathrm{T}} \mathrm{C}^{\mathrm{T}}$ and related taxa

\begin{tabular}{|c|c|c|c|c|c|c|c|c|}
\hline \multirow[b]{2}{*}{ Strain } & \multicolumn{8}{|c|}{$\%$ 16S rDNA sequence similarity } \\
\hline & 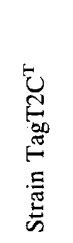 & 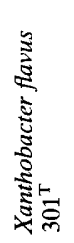 & 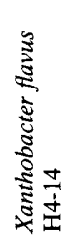 & 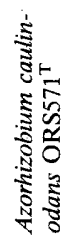 & 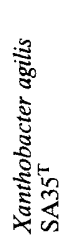 & 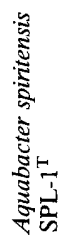 & 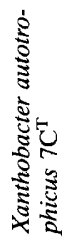 & 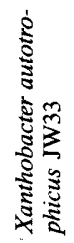 \\
\hline Xanthobacter flavus $301^{\mathrm{T}}$ & 98.1 & & & & & & & \\
\hline Xanthobacter flavus $\mathrm{H} 4-14$ & 98.0 & 99.9 & & & & & & \\
\hline Azorhizobium caulinodans ORS571 & 97.2 & 98.2 & 98.2 & & & & & \\
\hline Xanthobacter agilis $\mathrm{SA} 35^{\mathrm{T}}$ & 97.2 & 98.1 & 98.0 & 97.5 & & & & \\
\hline Aquabacter spiritensis SPL-1 ${ }^{\mathbf{T}}$ & 97.5 & 97.1 & 97.0 & 96.9 & 97.0 & & & \\
\hline Xanthobacter autotrophicus $7 \mathrm{C}^{\mathrm{T}}$ & 97.0 & 97.6 & 97.5 & 96.9 & 96.9 & 97.3 & & \\
\hline Xanthobacter autotrophicus JW33 & 96.9 & 97.5 & 97.4 & 96.8 & 96.8 & 97.2 & 99.9 & \\
\hline Rhodoplanes roseus DSM $5909^{\mathrm{T}}$ & 92.3 & 92.0 & 92.0 & 92.5 & 92.1 & 92.0 & 92.4 & 92.3 \\
\hline
\end{tabular}

study further the relationship between the plant and the bacterium to determine whether the association is specific, serendipitous, or opportunistic.

The morphological, biochemical, and physiological characteristics of strain TagT $2 \mathrm{C}^{\mathrm{T}}$ led us to classify this organism as a Xanthobacter species $(28,41,43)$. The phylogenetic coherence of the genus Xanthobacter has, however, recently been shown to be questionable (32). The results of the $16 \mathrm{~S}$ rDNA sequence analysis clearly show that strain TagT2 $\mathrm{C}^{\mathbf{T}}$ is a member of the phylogenetic cluster comprising members of the genera Aquabacter, Azorhizobium, and Xanthobacter. In a previous study workers demonstrated that these three genera are intermixed and that there is no clear phylogenetic cluster for the Xanthobacter species (32). The addition of the TagT2C $\mathrm{C}^{\mathrm{T}}$ sequence to the data set has not changed the situation. The bootstrap analysis showed that although the Aquabacter-Azorhizobium-Xanthobacter cluster was recovered in all cases, the branch points within the cluster were not significant. Consideration of the $16 \mathrm{~S}$ rDNA sequence data alone does not allow distinction between the following two possibilities: (i) that all members of the Aquabacter-Azorhizobium-Xanthobacter cluster are species of the genus Xanthobacter; and (ii) that each distinct lineage represents an individual genus. As comprehensive phenotypic and chemotaxonomic data are not available to provide unequivocal support for either of these options, we sought to establish to which of the three genera strain TagT2 $\mathrm{C}^{\mathrm{T}}$ is most similar on the basis of physiological and biochemical characteristics.

The three genera have many properties in common, including the same DNA G+C content (Table 3), the inability to

TABLE 3. Distinguishing properties of strain TagT2C $\mathrm{C}^{\mathrm{T}}$ and the gram-negative genera Xanthobacter, Azorhizobium, and Aquabacter ${ }^{a}$

\begin{tabular}{|c|c|c|c|c|}
\hline Characteristic & Strain TagT2C & Xanthobacter & Azorhizobium & Aquabacte \\
\hline Pleomorphism & $+^{b}$ & + & - & - \\
\hline DNA G $+\mathrm{C}$ content $(\mathrm{mol} \%)$ & 68 & $67-69$ & $66-68$ & 67 \\
\hline Legume nodule symbiont & - & - & + & - \\
\hline Presence of gas vacuoles & - & - & - & + \\
\hline Peritrichous flagella & + & \pm & + & $?^{c}$ \\
\hline Yellow colony pigmentation & + & + & - & - \\
\hline Cream-white colony pigmentation & - & - & + & + \\
\hline Slime production & + & \pm & - & $(-)^{d}$ \\
\hline Fixation of dinitrogen & + & + & + & - \\
\hline $\begin{array}{l}\text { Autotrophic fixation of } \mathrm{CO}_{2} \text { with ribulose } \\
\text { bisphosphate carboxylase }\end{array}$ & + & + & - & - \\
\hline \multicolumn{5}{|l|}{ Growth on: } \\
\hline Galactose & + & + & - & - \\
\hline Fructose & + & + & - & - \\
\hline Sucrose & + & + & - & - \\
\hline Lactose & + & + & - & - \\
\hline Formate & + & + & - & - \\
\hline Methylamine & + & + & - & $\mathrm{ND}^{e}$ \\
\hline Methanol & + & + & - & - \\
\hline Ethanol & + & + & - & - \\
\hline Hydrogen $+\mathrm{CO}_{2}$ & + & + & ND & ND \\
\hline Thiosulfate $+\mathrm{CO}_{2}$ & + & + & ND & ND \\
\hline
\end{tabular}

${ }^{a}$ Data from references $9,15,28,34,41$, and 43 .

${ }^{b}+$, positive; -, negative; \pm , characteristic varies in degree among species in response to growth conditions and methods of preparation (43).

${ }^{c}$ Organisms are flagellated, but the insertion position has not been reported.

${ }^{d} \mathrm{~A}$ capsule is present, and colonies are shiny, but slime production has not been reported.

${ }^{e} \mathrm{ND}$, not determined. 
denitrify, and the ability to grow on a variety of common substrates, but they also differ in a number of details (Table 3 ). It is clear from the characteristics listed in Table 3 that strain TagT $2 \mathrm{C}^{\mathrm{T}}$ has many more features in common with the genus Xanthobacter than with either the genus Azorhizobium or the genus Aquabacter, including its pleomorphism, pigmentation, chemolithoautotrophy on thiosulfate and hydrogen, and ability to grow on several $C_{1}$ compounds and various sugars. These characteristics support inclusion of strain TagT2 $\mathrm{C}^{\mathrm{T}}$ in the genus Xanthobacter, as do the results of the 16S rDNA sequence analysis. In the $16 \mathrm{~S}$ rDNA sequence analysis strain TagT2C ${ }^{\mathrm{T}}$ fell in the Aquabacter-Azorhizobium-Xanthobacter cluster and exhibited 97 to $98 \%$ sequence similarity to members of all three genera (Table 2), but was clearly quite distinct at the species level (Fig. 2). Previous work in which DNA-DNA hybridizations among species of these genera were performed showed that members of the genus Azorhizobium exhibited less than $20 \%$ binding to DNA from Xanthobacter autotrophicus or Xanthobacter flavus (9). While the relatedness of the genera of this cluster and the relatedness of the Xanthobacter spp. were clearly shown by the $16 \mathrm{~S}$ rDNA sequences and DNA-rRNA hybridization data $(9,32)$, DNA-DNA hybridization data showed that the Xanthobacter spp. are distinct from each other (17), and the levels of DNA-DNA homology among $X$. autotrophicus, $X$. flavus, and Xanthobacter agilis were recently shown to range from 17 to $31 \%$ (8). These data have little value for making precise phylogenetic placements (38) and did not justify the use of DNA-DNA hybridization with strain TagT2 $\mathrm{C}^{\mathrm{T}}$ at this time. If a future taxonomic rearrangement were to result in all of the members of this cluster being combined into the genus Xanthobacter (32), then strain TagT $2 \mathrm{C}^{\mathrm{T}}$ would continue to represent a distinct species of this genus.

Description of Xanthobacter tagetidis sp. nov. Xanthobacter tagetidis (ta.ge.ti'dis. M. L. n., of Tagetes, the marigold genus of flowering plants).

(i) Morphology. Colonies are low, entire, smooth, convex, mucoid, and egg yolk yellow. Cells are gram-negative, pleomorphic, short, fat rods $(0.5$ by $1.0 \mu \mathrm{m})$ with large, dark inclusion bodies which may occur at one or both ends of the cells. Motile. No spores are produced. A capsule is formed.

(ii) Cellular characteristics. The $\mathrm{G}+\mathrm{C}$ content of the DNA is $68 \pm 2 \mathrm{~mol} \%$ (as determined by the UV spectroscopy and melting point methods). The predominant ubiquinone is coenzyme Q10, and some coenzyme Q8 is present. Ribulose bisphosphate carboxylase is present in thiosulfate-grown cells $\left(108 \pm 6 \mathrm{nmol}\right.$ of $\mathrm{CO}_{2} \mathrm{fixed} / \mathrm{min} / \mathrm{mg}$ of cell extract protein $)$. Catalase and oxidase positive.

(iii) Growth characteristics. Obligately aerobic but potentially microaerophilic. For growth on $\mathrm{T} 2 \mathrm{C}$ the temperature range is 4 to $43^{\circ} \mathrm{C}$, the optimum temperature is 28 to $31^{\circ} \mathrm{C}$; and the optimum $\mathrm{pH}$ is 7.6 to 7.8 ( $\mathrm{pH}$ range tested, $\mathrm{pH} 6.8$ to 8.7 ). The initial rates of growth on $\mathrm{T} 2 \mathrm{C}$ in static cultures are similar to those in shaken cultures. Static cultures produce less slime than shaken cultures.

(iv) Metabolic characteristics. Chemoorganotroph characterized by an ability to grow on substituted thiophenes; facultative chemolithoautotroph on inorganic sulfur compounds and hydrogen; facultative methylotroph. Uses molecular dinitrogen as a nitrogen source. Utilizes T2A, T2C, thiophene-3carboxylate, dibenzothiophene, furan-2-carboxylate, pyrrole-2carboxylate, thiosulfate, tetrathionate (with added $\mathrm{CO}_{2}$ ), sulfide, hydrogen (with added $\mathrm{CO}_{2}$ ), carbonyl sulfide, carbon disulfide, methylamine (with added $\mathrm{CO}_{2}$ ), methanol, dimethyl sulfide, methanethiol, formate, acetate, ethanol, succinate, pyruvate, citrate, yeast extract, nutrient broth, galactose, sucrose, fructose, and glucose. In sulfate-free medium, T2C sup- ports growth as a sole source of carbon, energy, and sulfur. Inhibited by ampicillin and chloramphenicol.

(v) Habitat. The organism has been isolated only from the root balls of marigold plants ( $T$. patula and $T$. erecta).

(vi) Type strain. $X$. tagetidis TagT2C was isolated from a T. patula root ball and has been deposited as the type strain of the species in the Deutsche Sammlung von Mikroorganismen und Zellkulturen as strain DSM11105. This strain is one of several apparently identical strains isolated from $T$. patula and T. erecta.

We propose that on the basis of its morphological and physiological characteristics, including its facultative autotrophy on hydrogen and thiosulfate, its ability to grow by using dinitrogen as a nitrogen source, the $\mathrm{G}+\mathrm{C}$ content of its DNA, its levels of 16S rDNA sequence homology with other Xanthobacter spp., and its association with thiophene-producing marigold plants, strain TagT2C should be included in the genus Xanthobacter as the type strain of a new species, $X$. tagetidis.

\section{ACKNOWLEDGMENTS}

This work was supported in part by Natural Environment Research Council grants GR9/1024 and GR9/1176 to A.P.W. and by a Biotechnology and Biological Sciences Research Council Studentship to A.N.P.

We are grateful to Hans G. Trüper for grammatical advice on the correct specific epithet for the organism. We are indebted to Tony Brain (King's College Electron Microscopy Unit) for assistance with scanning and transmission electron microscopy.

\section{REFERENCES}

1. Amphlett, M. J. 1968. The microbiological transformation of sulphur-containing aromatic compounds. Ph.D. thesis. University of Wales, Cardiff, Wales.

2. Amphlett, M. J., and A. G. Callely. 1969. The degradation of 2-thiophenecarboxylic acid by a Flavobacterium species. Biochem. J. 112:12-13.

3. Brosius, J., M. L. Palmer, P. J. Kennedy, and H. F. Noller. 1978. Complete nucleotide sequence of the 16S ribosomal RNA gene from Escherichia coli. Proc. Natl. Acad. Sci. USA 75:4801-4805.

4. Buitelaar, R. M., M. T. Cesario, and J. Tramper. 1992. Elicitation of thiophene production by hairy roots of Tagetes patula. Enzyme Microb. Technol. 14:2-7.

5. Cawse, P. A. 1967 . The determination of nitrate in soil solutions by ultraviolet spectrophotometry. Analyst 92:311-315.

6. Cripps, R. E. 1971. Microbial metabolism of aromatic compounds containing sulphur. Ph.D. thesis. University of Warwick, Warwick, United Kingdom.

7. Cripps, R. E. 1973. The microbial metabolism of thiophene-2-carboxylate. Biochem. J. 134:353-366.

8. Doronina, N. V., Y. A. Trotsenko, V. I. Krauzova, and N. E. Suzina. 1996 New methylotrophic isolates of the genus Xanthobacter. Microbiology (Engl. transl. Mikrobiologiya) 65:217-224.

9. Dreyfus, B., J. L. Garcia, and M. Gillis. 1988. Characterization of Azorhizobium caulinodans gen. nov., sp. nov., a stem-modulating nitrogen-fixing bacterium isolated from Sesbania rostrata. Int. J. Syst. Bacteriol. 38:89-98.

10. Evans, J. S., and W. A. Venables. 1990. Degradation of thiophene-2-carboxylate, furan-2-carboxylate, pyrrole-2-carboxylate and other thiophene derivatives by the bacterium Vibrio YC1. Appl. Microbiol. Biotechnol. 32:715720

11. Felsenstein, J. 1985. Confidence limits on phylogenies: an approach using the bootstrap. Evolution 39:783-789.

12. Felsenstein, J. 1993. PHYLIP (phylogenetic inference package), version 3.5.1. Department of Genetics, University of Washington, Seattle.

13. Fredericq, E., A. Oth, and F. Fontaine. 1961. The ultraviolet spectrum of deoxyribonucleic acids and their constituents. J. Mol. Biol. 3:11-17.

14. Hausen, B. M., and B. Helmke. 1995. Butenylbithiophene, alpha-terthienyl and hydroxytremetone as contact allergens in cultivars of marigold (Tagetes sp.). Contact Dermatitis 33:33-37.

15. Irgens, R. I., K. Kersters, P. Segers, M. Gillis, and J. T. Staley. 1991 Aquabacter spiritensis, gen. nov., sp. nov. an anaerobic, gas-vacuolate aquatic bacterium. Syst. Appl. Microbiol. 9:254-257.

16. Jacobs, J. J. M. R., A. Engelberts, A. F. Croes, and G. J. Wullems. 1994 Thiophene synthesis and distribution in young developing plants of Tagetes patula and Tagetes erecta. J. Exp. Bot. 45:1459-1466.

17. Jenni, B., M. Aragno, and J. Wiegel. 1987. Numerical analysis and DNA DNA hybridization studies on Xanthobacter and emendation of Xanthobacter flavus. Syst. Appl. Microbiol. 9:247-253. 
18. Jordan, S. L., A. Kraczkiewicz-Dowjat, D. P. Kelly, and A. P. Wood. 1995. Novel eubacteria able to grow on carbon disulfide. Arch. Microbiol. 163 $131-137$.

19. Juhl, M. J., and D. P. Clark. 1990. Thiophene-degrading Escherichia col mutants possess sulfone oxidase activity and show altered resistance to sulfur-containing antibiotics. Appl. Environ. Microbiol. 56:3179-3185.

20. Jukes, T. H., and C. R. Cantor. 1969. Evolution of protein molecules, p. 21-132. In $\mathrm{H}$. N. Munro (ed.), Mammalian protein metabolism. Academic Press, New York, N.Y.

21. Kanagawa, T., and D. P. Kelly. 1987. Degradation of substituted thiophenes by bacteria isolated from activated sludge. Microb. Ecol. 13:47-57.

22. Kelly, D. P., and A. P. Wood. 1994. Synthesis and determination of thiosul fate and polythionates, p. 475-501. In H. D. Peck and J. LeGall (ed.) Methods in enzymology--inorganic sulfur metabolism. Academic Press, Orlando, Fla.

23. Kelly, D. P., L. A. Chambers, and P. A. Trudinger. 1969. Cyanolysis and spectrophotometric estimation of trithionate in mixture with thiosulfate and tetrathionate. Anal. Chem. 41:898-901.

24. Kilbane, J. J., and K. Jackowski. 1992. Biodesulfurization of water-soluble coal-derived material by Rhodococcus rhodochrous IGTS8. Biotechnol. Bioeng. 40:1107-1114.

25. Maidak, B. L., N. Larsen, M. J. McCaughey, R. Overbeek, G. J. Olsen, K. Fogel, J. Blandy, and C. R. Woese. 1994. The Ribosomal Database Project. Nucleic Acids Res. 22:3485-3487.

26. Mandel, M., and J. Marmur. 1968. Use of ultra-violet absorbance-temperature profile for determining the guanine plus cytosine content of DNA Methods Enzymol. 12B:195-206.

27. Marmur, J. 1961. A procedure for the isolation of deoxyribonucleic acid from micro-organisms. J. Mol. Biol. 3:208-218.

28. Meijer, W. G., L. M. Croes, B. Jenni, L. G. Lehmicke, M. E. Lidstrom, and L. Dijkhuizen. 1990. Characterization of Xanthobacter strains H4-14 and 25a and enzyme profiles after growth under autotrophic and heterotrophic conditions. Arch. Microbiol. 153:360-367.

29. Mukundan, U., and M. A. Hjortso. 1990. Thiophene content in normal and transformed root cultures of Tagetes erecta: a comparison with thiophene content in roots of intact plants. J. Exp. Bot. 41:1497-1501.

30. Omori, T., L. Mouna, L. Saiki, and T. Kodama. 1992. Desulfurization of dibenzothiophene by Corynebacterium sp. strain SY1. Appl. Environ. Microbiol. 58:911-915.

30a.Padden, A. N., and A. P. Wood. Unpublished data.

31. Perich, M. J., C. Wells, W. Bertsch, and K. E. Tredway. 1995. Isolation of the insecticidal components of Tagetes minuta (Compositae) against mosquito larvae and adults. J. Am. Mosquito Control Assoc. 11:307-310.

32. Rainey, F. A., and J. Wiegel. 1996. 16S ribosomal DNA sequence analysis confirms the close relationship between the genera Xanthobacter, Azorhizobium, and Aquabacter and reveals lack of phylogenetic coherence among
Xanthobacter species. Int. J. Syst. Bacteriol. 46:607-610.

33. Rainey, F. A., N. Ward-Rainey, R. M. Kroppenstadt, and E. Stackebrandt 1996. The genus Nocardiopsis represents a phylogenetically coherent taxon and a distinct actinomycete lineage: proposal of Nocardiopsiaceae fam. nov. Int. J. Syst. Bacteriol. 46:1088-1092.

34. Reding, H. K., G. L. M. Croes, L. Dijkhuizen, and J. Wiegel. 1992. Emendation of Xanthobacter flavus as a motile species. Int. J. Syst. Bacteriol. 42:309-311.

35. Romagnoli, C., D. Mares, M. P. Fasulo, and A. Bruni. 1994. Antifungal effects of alpha-terthienyl from Tagetes patula on five dermatophytes. Phytother. Res. 8:332-336.

36. Saenz Carbonell, L. A., I. E. Maldonado Mendoza, O. Moreno Valenzula, R. Ciauuiyz, M. Lopez Meyer, C. Oropeza, and V. M. Loyola Vargas. 1993. Effects of medium $\mathrm{pH}$ on the secondary metabolites from roots of Datura stramonium, Catharanthus roseus, and Tagetes patula cultured in vitro. Appl. Biochem. Biotechnol. 38:257-267.

37. Saitou, N., and M. Nei. 1987. The neighbor-joining method: a new method for reconstructing phylogenetic trees. Mol. Biol. Evol. 4:406-425.

38. Stackebrandt, E., and B. M. Goebel. 1994. Taxonomic note: a place for DNA-DNA reassociation and $16 \mathrm{~S}$ rRNA sequence analysis in the present species definition in bacteriology. Int. J. Syst. Bacteriol. 44:846-849.

39. Talou, J. R., O. Cascone, and A. M. Giulietta. 1994. Content of thiophenes in transformed root cultures of Argentinian species of Tagetes. Planta Med. 60:260-262.

40. Tuovinen, O. H., and D. P. Kelly. 1973. Studies on the growth of Thiobacillus ferrooxidans. Arch. Mikrobiol. 88:285-298.

41. Urakami, T., H. Araki, and K. Komagata. 1995. Characteristics of newly isolated Xanthobacter strains and fatty acid compositions and quinone systems in yellow-pigmented hydrogen-oxidizing bacteria. Int. J. Syst. Bacteriol. 45:863-867.

42. van Afferden, M., S. Schacht, J. Klein, and H. G. Trüper. 1990. Degradation of dibenzothiophene by Brevibacterium sp. DO. Arch. Microbiol. 153:324 328 .

43. Wiegel, J. 1992. The genus Xanthobacter, p. 2365-2383. In A. Balows, H. G. Trüper, M. Dworkin, W. Harder, and K.-H. Schleifer (ed.), The prokaryotes, 2nd ed. Springer-Verlag, New York, N.Y.

44. Wood, A. P., and D. P. Kelly. 1983. Autotrophic, mixotrophic and heterotrophic growth with denitrification by Thiobacillus A2 under anaerobic conditions. FEMS Microbiol. Lett. 16:363-370.

45. Wood, A. P., and D. P. Kelly. 1985. Physiological characteristics of a new thermophilic obligately chemolithotrophic Thiobacillus species, Thiobacillus tepidarius. Int. J. Syst. Bacteriol. 35:434-437.

46. Wood, A. P., and D. P. Kelly. 1986. Chemolithotrophic metabolism of the newly-isolated moderately thermophilic, obligately autotrophic Thiobacillus tepidarius. Arch. Microbiol. 144:71-77. 